\title{
Report on Overcoming the Poor Quality of ApaI Pulsotypes with a Short Review on PFGE for Listeria monocytogenes
}

\author{
DARJA KUŠAR*, MAJA KAVALIČ, MATJAŽ OCEPEK and IRENA ZDOVC \\ Institute of Microbiology and Parasitology, Veterinary Faculty, University of Ljubljana, Ljubljana, Slovenia \\ Submitted 16 April 2012, accepted 15 July 2013
}

Abstract

\begin{abstract}
Since listeriosis, caused by Listeria monocytogenes, is one of the important concerns of public health in Europe related to foodborne zoonoses, an efficient protocol for isolate typing is necessary when performing epidemiological studies. Three standardized PFGE protocols available for L. monocytogenes were briefly reviewed. Since observing a poor-quality of ApaI pulsotypes in our laboratory, enzymes from three different manufacturers were compared. The obtained pulsotypes showed that restriction digestion with ApaI from New England BioLabs should be complemented with a subsequent overnight incubation of PFGE plugs in TE buffer for better performance.
\end{abstract}

Ke y word s: Listeria monocytogenes, ApaI restriction, quality of pulsotypes, PFGE, standardized protocol

Listeriosis is caused by bacteria of the genus Listeria, mostly by Listeria monocytogenes, and is affecting both animals and humans (Fenlon, 1999). A substantial proportion of herd animals may shed significant numbers of L. monocytogenes in faeces and milk (European Food Safety Authority, 2010; Wesley, 2007). Transmission to humans most commonly occurs by consumption of raw animal products (Wesley, 2007), especially by foods contaminated during manufacturing and postprocessing (Boerlin and Piffaretti, 1991; Hitchins and Whiting, 2001; Tompkin, 2002). In humans, foodborne listeriosis usually occurs in pregnant women, neonates or immunocompromised adults (Painter and Slutsker, 2007). L. monocytogenes is the most important cause of death from foodborne infections in industrialized countries and though the human infections are rare, they are very important given the associated high mortality rate (European Food Safety Authority, 2010).

Pulsed-field gel electrophoresis (PFGE) is currently considered the gold standard for epidemiological studies of bacterial foodborne pathogens, including L. monocytogenes (Giovannacci et al., 1999; Graves et al., 2009). Following a standardized protocol generating good-quality results, the obtained PFGE profiles (pulsotypes) can be subjected to a computer-based processing and compared at the international level. For L. monocytogenes, the original standardized protocol [A] was launched in 1998 (Graves and Swaminathan, 2001) by the PulseNet, today known as the PulseNet
International uniting seven laboratory networks (e.g. PulseNet USA and PulseNet Europe). Later, the original protocol A was optimized and dispatched in 2009 by the European Union Reference Laboratory (EURL) to the participant European laboratories as the EURL in-house method [B1]. It was similar to the updated PulseNet USA PFGE standardized protocol [B2] published soon after (Halpin et al., 2010). Major differences between the two were presented previously (Félix et al., 2012). In brief, the $\mathrm{B} 2$ protocol, in comparison to B1, recommends lower cell density per PFGE plug, the preparation of lysozyme solution in TE buffer (vs. water) and incubation at $56^{\circ} \mathrm{C}$ (vs. $37^{\circ} \mathrm{C}$ ), and higher amount of the restriction enzymes and the total volume of restriction mixtures $(200 \mu \mathrm{l}$ vs. $100 \mu \mathrm{l})$. In comparison to $\mathrm{A}$, both $\mathrm{B} 1$ and $\mathrm{B} 2$ protocols recommend a much lower amount of $A p a \mathrm{I}$ in the restriction digests, namely $10 \mathrm{U}(\mathrm{B} 1)$ and $50 \mathrm{U}$ (B2) in comparison to the original 160-200 U (A) per sample, and the addition of bovine serum albumin (BSA) to the restriction mixtures even when not recommended by the manufacturer.

The aim of the present paper was to present how the selection of different suppliers/protocols ApaI restriction can affect the quality of L. monocytogenes ApaI pulsotypes, exerting higher complexity (14-17 bands expected) than AscI profiles (6-12; Carriere et al., 1991). In our study, PFGE employing restriction enzyme ApaI was performed as recommended by the original protocol A. As a molecular size-marker,

\footnotetext{
* Corresponding author: D. Kušar, Institute of Microbiology and Parasitology, Veterinary Faculty, University of Ljubljana, Gerbičeva
} 60, SI-1115 Ljubljana, Slovenia; phone: +386 14779 158; fax: +386 14779 352; e-mail: darja.kusar@vf.uni-lj.si 
Salmonella enterica serovar Braenderup (strain H9812, digested with XbaI) was used (Hunter et al., 2005). Electrophoresis was performed on CHEF-DR II apparatus (BioRad, Hercules, CA, USA). Three different ApaI enzymes were compared. First, $A p a \mathrm{I}$ from Roche Diagnostics [RD] (Mannheim, Germany) with $40 \mathrm{U} / \mu \mathrm{l}$ stock concentration and the optimal incubation temperature of $30^{\circ} \mathrm{C}$, since recommended in $\mathrm{A}$ and $\mathrm{B} 1$ (and in $\mathrm{B} 2$ as the protocol refers to $\mathrm{A}$ regarding the restriction enzymes). Second, ApaI from Thermo Fischer Scientific [TS] (Waltham, MA, USA; formerly purchased under a trademark of Fermentas, Vilnius, Lithuania) with $10 \mathrm{U} / \mu \mathrm{l}$ concentration and $37^{\circ} \mathrm{C}$ incubation temperature, since manufactured by an established company in the field of restriction enzymes. Third, ApaI from New England BioLabs [NEB] (Ipswich, MA, USA) with $50 \mathrm{U} / \mu \mathrm{l}$ concentration and $25^{\circ} \mathrm{C}$ incubation temperature, since recommended for $A s c \mathrm{I}$ restriction in $\mathrm{A}$ and B1. No separately purchased BSA was included in any of the ApaI restriction mixtures as not yet recommended in A; BSA is, however, already present in the restriction buffer from TS and supplied separately with ApaI (but not with AscI) enzyme from NEB. Since given as a potential stopping point, incubation of PFGE plugs in TE buffer (0.01 M Tris-EDTA, pH 8.0) was tested after restriction using ApaI from NEB, namely the restriction mixture was removed and replaced by equal volume of TE for an overnight (one-day) incubation of plugs at $4^{\circ} \mathrm{C}$ (Cooper, 2010).
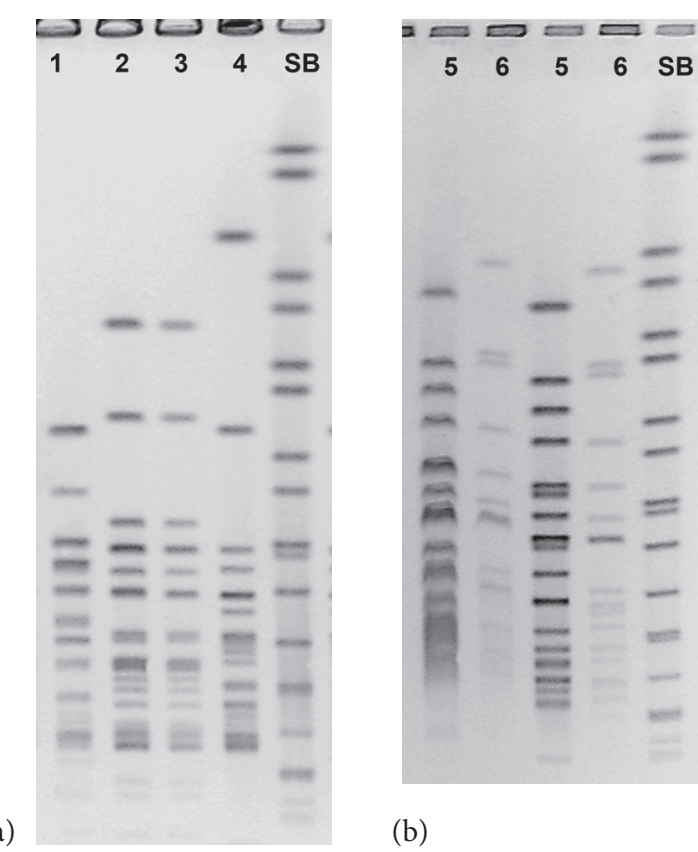

(b)

(c)
Selection of ApaI restriction enzymes purchased from different manufacturers can affect the quality of L. monocytogenes pulsotypes. ApaI from RD has been employed for several years in our laboratory, namely since 2006 when we started the PFGE typing of L. monocytogenes following the protocol $\mathrm{A}$, and we have been obtaining good-quality results (Fig. 1a). Later, ApaI from TS was tested and it also generated pulsotypes of satisfactory quality (Fig. 1b, lanes 3 and 4); however, the volume of enzyme solution needed for the preparation of restriction mixture was higher in comparison to ApaI from $\mathrm{RD}$ due to a lower concentration of the enzyme available from TS. This can be acknowledged as a drawback due to two aspects. First, since glycerol is present in the storage buffer of enzymes, larger consumption of enzyme solution leads to a higher glycerol concentration in the restriction mixture, possibly conditioning the star activity of restriction enzymes (Freeman, 2011). Second, larger consumption demands for larger enzyme stocks. Therefore, an enzyme with higher concentration was tested, namely ApaI from NEB. In comparison to RD and TS, NEB enzyme generated poor-quality pulsotypes (Fig. 1b, lanes 1 and 2; Fig. 1c). However, when an overnight TE-incubation of plugs after restriction was tested, the obtained pulsotypes markedly improved (Fig. 1d).

It had been shown before that enzyme digestion was not optimal when e.g. BSA was not included in the restriction mixture, not enough or too many units of restriction enzyme were used, and incubation time,

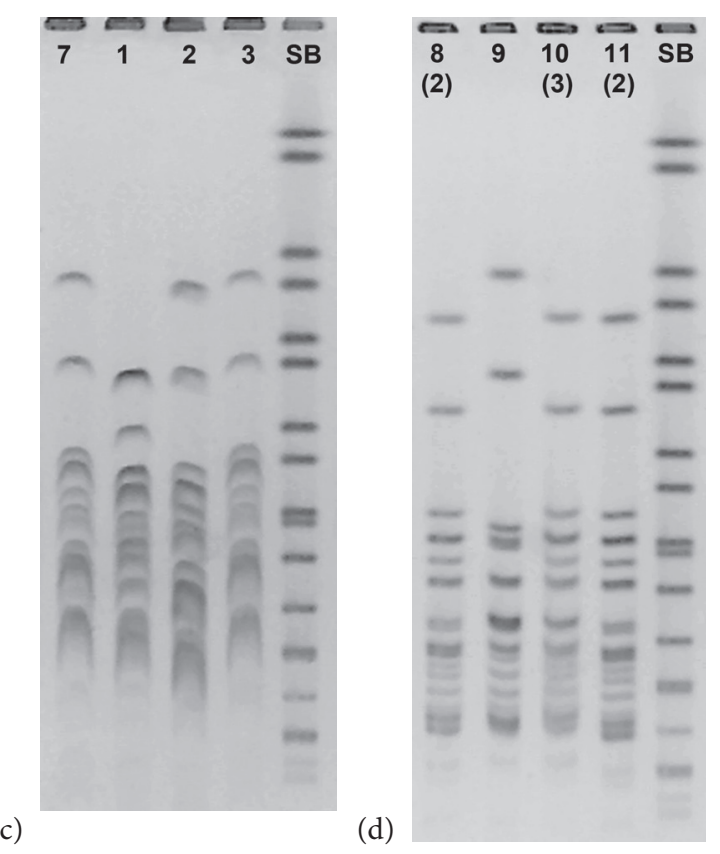

Fig. 1. PFGE separation of ApaI fragments from L. monocytogenes isolates. Salmonella Braenderup strain H9812 (SB) was employed as size standard.

(a) ApaI from Roche Diagnostics, isolates 1-4;

(b) ApaI from New England BioLabs (NEB; lanes 1 and 2) and from Thermo Fischer Scientific (lanes 3 and 4), isolates 5 and 6;

(c) ApaI from NEB, isolates 1-3 and 7;

(d) ApaI from NEB followed by an overnight incubation in TE buffer, isolates 8-11 (8 and 11 showed an identical pulsotype as isolate 2, and 10 identical as isolate 3 , as indicated in the parentheses) 
temperature or buffer were not correct (Freeman, 2011). However, in the case of $A p a \mathrm{I}$ from NEB in our study, digestion did not seem to be compromised in such manner as the number of bands, appearance of ghost/ shadow bands, resolution or high background could not be discussed as a main problem. Band distortion was a much more serious issue impairing the pulsotype quality and interpretation. Wavy bands, as seen in Figs. $1 \mathrm{~b}$ and $1 \mathrm{c}$, were observed before in plugs digested with ApaI from NEB, in the presence of BSA and with different laboratory personnel (Freeman, 2012). It was concluded that band distortion could be directly correlated with the units of restriction enzyme added to the master mix, namely an increasing distortion was observed when 100 or more U of ApaI were employed (in our study, $200 \mathrm{U}$ were added according to the original protocol A). Moreover, the anomaly was observed with new enzyme lots in January 2012 (Freeman, 2012). In our study, $A p a \mathrm{I}$ with a lot number higher from the ones tested by Freeman (2012) was used, assuming the enzyme was also released in January 2012 or later.

It can be concluded that variations in the standardized PFGE protocols can, among other reasons discussed elsewhere like the quality of water, in-house prepared buffers, laboratory personnel or others, appear due to the lot-to-lot variations of restriction enzymes from the same manufacturer or between enzymes from different manufacturers. The EURL in-house method for the PFGE typing of L. monocytogenes (protocol B1) recommends the use of $A s c$ I from NEB, but $A p a \mathrm{I}$ from $\mathrm{RD}$, and comments that the use of materials and reagents of other suppliers could generate deviation in the results. It was also recommended (protocols B1 and B2) that the amount of restriction enzymes, especially of ApaI, should not be in excess when aiming for pulsotypes of high quality. In other studies, an overnight (or longer) incubation in TE buffer was not suggested as a curative step in the protocol of ApaI restriction; however, improved the quality of pulsotypes obtained in our study when testing ApaI from NEB.

\section{Acknowledgements}

The work was financially supported by the Slovenian Research Agency and the Ministry of Agriculture and the Environment of Slovenia (grant no. V4-1106). Alenka Magdalena Usenik is gratefully acknowledged for technical assistance.

\section{Literature}

Boerlin P. and J.C. Piffaretti. 1991. Typing of human, animal food and environmental isolates of Listeria monocytogenes by multilocus enzyme electrophoresis. Appl. Environ. Microbiol. 57: 1624-1629.

Carriere C., A. Allardet-Servent, G. Bourg, A. Audurier and M. Ramuz. 1991. DNA polymorphism in strains of Listeria monocytogenes. J. Clin. Microbiol. 29: 1351-1355.
Cooper K. 2010. PFGE: general overview and troubleshooting tips; Available from: www.pulsenetinternational.org/SiteCollectionDocuments/pfge/PFGE_troubleshooting.pdf; $16^{\text {th }}$ April 2013, date last accessed.

European Food Safety Authority. 2010. The community summary report on trends and sources of zoonoses, zoonotic agents and foodborne outbreaks in the European Union in 2008. EFSA Journal 8: 1496. Parma, Italy. EFSA; Available from: www.efsa.europa.eu/en/ efsajournal/doc/1496.pdf; $16^{\text {th }}$ April 2013, date last accessed.

Félix B., T.T. Dao, B. Lombard, A. Asséré, A. Brisabois and S. Roussel. 2012. The use of pulsed field gel electrophoresis in Listeria monocytogenes sub-typing - harmonization at the European Union level, pp. 241-254. In: Magdeldin S. (ed). Gel Electrophoresis - Principles and Basics. InTech, Rijeka, Croatia; Available from: www.intechopen.com/books/gel-electrophoresis-principles-andbasics/harmonization-of-listeria-monocytogenes-pfge-sub-typingat-european-union-level; $16^{\text {th }}$ April 2013, date last accessed.

Fenlon D.R. 1999. Listeria monocytogenes in the natural environment, pp. 21-37. In: Ryser E.T. and E.H. Marth (eds). Listeria, Listeriosis, and Food Safety. $2^{\text {nd }}$ ed. Marcel Dekker Inc., New York, USA. Freeman M. 2011. PFGE: tips and tricks to success and interpretation of results for foodborne outbreak investigations - BioNumerics workshop for PulseNet participants, 15 April 2011; Available from: www.pulsenetinternational.org/SiteCollectionDocuments/ bionumerics/15-PFGE_tips_tricks_interpretation2011_MF.pdf; $16^{\text {th }}$ April 2013, date last accessed.

Freeman M. 2012. 2012 PulseNet PFGE laboratory update: everything old is new again; Available from: www.aphl.org/conferences/ proceedings/Documents/2012/2012-PulseNet-OutbreakNet/016Freeman.pdf; $16^{\text {th }}$ April 2013, date last accessed.

Giovannacci I., C. Ragimbeau, S. Queguiner, G. Salvat, J.-L. Vendeuvre, V. Carlier and G. Ermel. 1999. Listeria monocytogenes in pork slaughtering and cutting plants: use of RAPD, PFGE and PCRREA for tracking and molecular epidemiology. Int. J. Food Microbiol. 53: $127-140$.

Graves L.M. and B. Swaminathan. 2001. PulseNet standardized protocol for subtyping Listeria monocytogenes by macrorestriction and pulsed-field gel electrophoresis. Int. J. Food Microbiol. 65: 55-62. Graves L.M., B. Swaminathan and S.B. Hunter. 2009. Subtyping Listeria monocytogenes, pp. 283-304. In: Ryser E.T. and E.H. Marth (eds). Listeria, Listeriosis, and Food Safety. $3^{\text {rd }}$ ed. CRC Press, Taylor and Francis Group, Boca Raton, FL, USA.

Halpin J.L., N.M. Garrett, E.M. Ribot, L.M. Graves and K.L. Cooper. 2010. Re-evaluation, optimization, and multilaboratory validation of the PulseNet-standardized pulsed-field gel electrophoresis protocol for Listeria monocytogenes. Foodborne Pathog. Dis. 7: 293-298.

Hitchins A.D. and R.C. Whiting. 2001. Food-borne Listeria monocytogenes risk assessment. Food Addit. Contam. 18: 1108-1117.

Hunter S.B., P. Vauterin, M.A. Lambert-Fair, M.S. Van Duyne, K. Kubota, L. Graves, D. Wrigley, T. Barrett and E. Ribot. 2005. Establishment of a universal size standard strain for use with the PulseNet standardized pulsed-field gel electrophoresis protocols: converting the national databases to the new size standard. J. Clin. Microbiol. 43: 1045-1050.

Painter J. and L. Slutsker. 2007. Listeriosis in humans, pp. 85-109. In: Ryser E.T. and E.H. Marth (eds). Listeria, Listeriosis, and Food Safety. $3^{\text {rd }}$ ed. CRC Press, Taylor and Francis Group, Boca Raton, FL, USA.

Tompkin R.B. 2002. Control of Listeria monocytogenes in the foodprocessing environment. J. Food Prot. 65: 709-725.

Wesley I.V. 2007. Listeriosis in animals, pp. 55-84. In: Ryser E.T. and E.H. Marth (eds). Listeria, Listeriosis, and Food Safety. $3^{\text {rd }}$ ed. CRC Press, Taylor and Francis Group, Boca Raton, FL, USA. 